\title{
Multiple long-term conditions within households and use of health and social care: a retrospective cohort study
}

\author{
Mai Stafford, PhD ${ }^{1 *}$, Sarah R Deeny, $\mathrm{PhD}^{1}$, Kathryn Dreyer, MSc ${ }^{1}$, Jenny Shand, \\ $\mathrm{PhD}^{2,3,4}$
}

${ }^{1}$ The Health Foundation, London, UK; ${ }^{2}$ UCLPartners, London, UK; ${ }^{3}$ Institute of Epidemiology \& Health Care, University College London, London, UK; ${ }^{4}$ Care City, Barking, UK

\begin{abstract}
Background: The daily management of long-term conditions falls primarily on individuals and informal carers, but the impact of household context on health and social care activity among people with multiple long-term conditions (MLTCs) is understudied.
\end{abstract}

Aim: To test whether co-residence with a person with MLTCs (compared with a co-resident without MLTCs) is associated with utilisation and cost of primary, community, secondary health care, and formal social care.

Design \& setting: Linked data from health providers and local government in Barking and Dagenham for a retrospective cohort of people aged $\geq 50$ years in two-person households in 2016-2018.

Method: Two-part regression models were applied to estimate annualised use and cost of hospital, primary, community, mental health, and social care by MLTC status of individuals and co-residents, adjusted for age, sex, and deprivation. Applicability at the national level was tested using the Clinical Practice Research Datalink (CPRD).

Results: Forty-eight per cent of people with MLTCs in two-person households were co-resident with another person with MLTCs. They were $1.14(95 \%$ confidence interval $[\mathrm{Cl}]=1.00$ to 1.30$)$ times

*For correspondence: mai. stafford@health.org.uk

Competing interest: The authors declare that no competing interests exist.

Received: 04 August 2020 Accepted: 10 September 2020

Published: 24 February 2021

(C)This article is Open Access: CC BY license (https://creativecommons.org/licenses/by/4.0/)

Author Keywords: comorbidity, multimorbidity, multiple conditions, inequalities, social context, socioeconomic factors

Copyright (C) 2021, The Authors; DOI:10.3399/BJGPO.2020.0134 as likely to have community care activity and $1.24(95 \% \mathrm{Cl}=0.99$ to 1.54$)$ times as likely to have mental health care activity compared with those co-resident with a healthy person. They had more primary care visits $(8.5[95 \% \mathrm{Cl}=8.2$ to 8.8$]$ versus $7.9[95 \% \mathrm{Cl}=7.7$ to 8.2$])$ and higher primary care costs. Outpatient care and elective admissions did not differ. Findings in national data were similar.

Conclusion: Care utilisation for people with MLTCs varies by household context. There may be potential for connecting health and community service input across household members.

\section{How this fits in}

It is known that care utilisation and cost are higher for people with multiple long-term conditions (MLTCs) but not whether this association varies by health status of household co-residents. Greater primary care, community care, and mental health care activity were found where a person with MLTCs was co-resident with another person with MLTCs. This affirms the need to identify and support informal carers. The potential to improve how health and care services are connected across people within a household should be considered. 


\section{Introduction}

Meeting the needs of people with MLTCs is a key challenge facing health and social care systems. In the UK, around 25\% of people (depending on the conditions included) have $\geq 2$ conditions and their care needs account for $>50 \%$ of primary and secondary care costs, and a substantial portion of community and social care costs. ${ }^{1-3}$ Trials of initiatives to improve outcomes and reduce hospital or emergency care use of those with MLTCs have not shown success, at least in the short term. ${ }^{4,5}$ Initiatives have focused on providing patient-centred care for people with MLTCs, ${ }^{6}$ but if elements of care use and costs are to be reduced then more research is needed on their drivers. The potential for considering the household context in the management of ongoing conditions has so far received little attention.

The daily responsibility for managing their conditions usually falls primarily on the individuals themselves and on their informal carers. Around half of carers in England provide care for someone in the same household. ${ }^{7}$ However, studies of the household context and its impact on service use and cost among people with MLTCs have focused on household size ${ }^{8}$ and not household members' health status. Co-residents are at increased risk of having long-term conditions ${ }^{9,10}$ because of shared lifestyle, ${ }^{11}$ social risk factors, and the tendency to select a similar partner. A co-resident's illness may make it more difficult for them to provide practical, financial, or emotional support.

This study examined whether co-residence with another person with MLTCs is associated with higher use and cost of primary, community, secondary health care, and formal social care. Difficulty in identifying households within electronic health records (EHRs) likely contributes to the lack of research in this area. To address this, a local sample of EHRs was used that were linked to household composition data from local authority records and the analysis was replicated in a national study where co-residence was inferred from anonymised address data.

\section{Method}

The study included people aged $\geq 50$ years in two-person households. The prevalence of MLTCs rises with age and the combination of conditions also varies with age, with mental and physical comorbidities being more prevalent at younger ages. ${ }^{1}$ The study, therefore, focuses on middle and older age, when people may be experiencing changes in health and functioning. People in households with $\geq 3$ occupants were excluded to remove institutions or situations where there could be multiple people providing help.

\section{Main analytical sample: Barking and Dagenham}

Linked information from local government services, health providers, and health commissioners includes sociodemographic, health, and household information alongside activity data for five care settings (primary care, hospital, community, inpatient and outpatient mental health services, and social care). Residents of Barking and Dagenham, a borough in outer London, were included from 1 April 2016 to 31 March 2018. Those who moved out of Barking and Dagenham or who died before the 1 April 2018 were excluded, given the known increase in healthcare utilisation at the end of life. ${ }^{12}$ Household composition was derived using the unique property reference number in local government records. The analytical sample was 9222 individuals in 4611 two-person households.

\section{Measuring MLTCs}

Long-term conditions associated with higher treatment needs, poorer quality of life, or greater risk of premature death were included. 1,13,14 Sixteen long-term mental and physical health conditions were identified from diagnosis codes recorded in primary care (see Supplementary Table S1). People with $\geq 2$ conditions were classified as having 'MLTCs' and those with 0-1 condition as 'healthy'. Individuals were assigned to one of four categories: person with MLTCs co-resident with healthy person (MLTCs/ healthy; the reference group); person with MLTCs co-resident with another (Both MLTCs); healthy person co-resident with healthy person (Both healthy); healthy person co-resident with person with MLTCs (healthy/MLTCs).

\section{Health and social care activity and cost}

The following health and social care activity and cost outcomes were examined over 2 years: number and cost of primary care consultations with a GP, nurse, or other clinical staff; days in hospital and 
cost of hospital care (broken down into outpatient consultations, elective admissions, non-elective admissions, and emergency department [ED] attendances); cost of mental health inpatient and outpatient care; cost of community health services; and cost of local government funded social care.

Local unit level costs were used for community and mental health activity and social care services. All other costs were based on activity using national reference costs for the relevant year. Mean cost for the relevant activity was used where an activity code could not be matched to a national reference cost. Costs were indexed to 2018 prices. See Supplementary Table S2 for more detail on the costing method.

\section{Statistical analysis}

The distributions of care costs and days in hospital show a substantial proportion of people having zero activity. Two-part mixture models were used to account for their semi-continuous distributions. The first part used a logistic model to estimate the likelihood of having any versus no care. The second part used a gamma model to estimate the cost or utilisation among the subset where this was nonzero. Sex, age group, deprivation (Index of Multiple Deprivation quintile for the patient's residence), and MLTC status were included as covariates for both parts. Mean costs and activity across both parts of the model combined were also estimated. Individual level analysis with robust standard errors allowed for the non-independence of individuals within households.

\section{Replication in a national sample}

Nationally representative data were obtained from the CPRD (approved protocol: ISAC17_150RMn2). CPRD comprises de-identified records of $>14$ million patients ${ }^{15}$ linked to Hospital Episode Statistics (HES) for consenting practices in England. Individuals were included who were registered in up-tostandard practices (derived by CPRD using information on continuity of recording and number of recorded deaths) from 1 April 2014 to 31 March 2016.

The CPRD pseudonymised family number (based on the first line of the patient's address) was used to select a sample where exactly two patients shared a family identifier and were registered within 1 year of each other. This excludes households where members are not registered at the same GP practice. From an initial random sample of 300000 children and adults with linked HES data, 10528 met inclusion criteria and formed the analytical sample for this study.

The presence of 36 mental and physical health conditions recorded in primary care ${ }^{16}$ was determined on 1 April 2014 based on diagnosis (using Read codes) and prescribing data (see Supplementary Table S3). There is considerable overlap with the 16 broader groups of long-term conditions included in the main analysis. GP and hospital care activity and costs were calculated using the same approach but mental health care, community health care, and social care data were not available.

\section{Results}

\section{Sample description: main sample}

The prevalence of MLTCs was $43 \%$ for those aged $\geq 50$ years living in two-person households in Barking and Dagenham. Forty-eight per cent of people with MLTCs lived with another person with MLTCs (Table 1). Older people and those in deprived areas were over-represented in households with two residents with MLTCs.

Over $97 \%$ of people had at least one primary care consultation, but over $30 \%$ had no outpatient attendance, $80 \%$ had no emergency department attendance, and over $80 \%$ had no inpatient admission (see Supplementary Table S4).

\section{Model results: main sample}

The association between each person's household MLTC status and the likelihood of having any care activity is shown in Table 2 (see column labelled 'OR for any activity'). The focus is on people with MLTCs co-resident with a person with or without MLTCs. Controlling for sex, age, and socioeconomic deprivation, the Both MLTCs group was $1.14(95 \% \mathrm{Cl}=1.00$ to 1.30$)$ times as likely to have any community care activity. In addition, the Both MLTCs group was 1.24 (95\% Cl=0.99 to 1.54 ) times as likely to have any mental health care activity, and $1.24(95 \% \mathrm{Cl}=0.96$ to 1.59$)$ times as likely to have any social care activity as the MLTCs/healthy reference group. 
Table 1 Barking and Dagenham and Clinical Practice Research Datalink sample characteristics

\begin{tabular}{|c|c|c|c|c|c|c|c|c|c|c|}
\hline & \multicolumn{2}{|c|}{$\begin{array}{l}\text { MLTCs/healthy } \\
\text { co-resident }\end{array}$} & \multicolumn{2}{|c|}{ Both MLTCs } & \multicolumn{2}{|c|}{$\begin{array}{c}\text { Healthy/MLTCs } \\
\text { co-resident }\end{array}$} & \multicolumn{2}{|c|}{ Both healthy } & \multicolumn{2}{|c|}{ All participants } \\
\hline & $n$ & row $\%$ & $n$ & row \% & $n$ & row \% & $n$ & row $\%$ & $n$ & $\mathrm{col} \%$ \\
\hline B \& D sample & 2049 & 22.2 & 1884 & 20.4 & 3240 & 35.1 & 2049 & 22.2 & 9222 & 100.0 \\
\hline \multicolumn{11}{|l|}{ Age, years } \\
\hline $50-59$ & 337 & 14.4 & 205 & 8.8 & 1240 & 53.1 & 554 & 23.7 & 2336 & 25.3 \\
\hline 60-69 & 620 & 20.9 & 566 & 19.1 & 1124 & 37.9 & 655 & 22.1 & 2965 & 32.2 \\
\hline 70-79 & 644 & 26.0 & 663 & 26.8 & 595 & 24.0 & 575 & 23.2 & 2477 & 26.9 \\
\hline$\geq 80$ & 448 & 31.0 & 450 & 31.2 & 281 & 19.5 & 265 & 18.4 & 1444 & 16.7 \\
\hline \multicolumn{11}{|l|}{ Sex } \\
\hline Male & 1044 & 22.7 & 928 & 20.1 & 1640 & 35.6 & 997 & 21.6 & 4609 & 50.0 \\
\hline Female & 1005 & 21.8 & 956 & 20.7 & 1600 & 34.7 & 1052 & 22.8 & 4613 & 50.0 \\
\hline
\end{tabular}

\section{IMD quintile}

\begin{tabular}{lcccccccccc}
1 (least deprived) & 0 & 0 & 0 & 0 & 0 & 0 & 0 & 0 & 0 & 0 \\
\hline 2 & 0 & 0 & 0 & 0 & 0 & 0 & 0 & 0 & 0 & 0 \\
\hline 3 & 192 & 21.7 & 163 & 18.4 & 339 & 38.3 & 192 & 21.7 & 886 & 9.6 \\
\hline 4 & 768 & 22.5 & 617 & 18.1 & 1263 & 37.0 & 770 & 22.5 & 3418 & 37.1 \\
\hline 5 (most deprived) & 1089 & 22.1 & 1104 & 22.4 & 1638 & 33.3 & 1087 & 22.1 & 4918 & 53.3 \\
\hline
\end{tabular}

Carer code

\begin{tabular}{lcccccccccc} 
Present & 134 & 31.2 & 158 & 36.8 & 81 & 18.9 & 56 & 13.1 & 429 & 4.7 \\
\hline Not present & 1915 & 21.8 & 1726 & 19.6 & 3159 & 35.9 & 1993 & 22.7 & 8793 & 95.3 \\
\hline CPRD sample & 2107 & 20.0 & 2940 & 27.9 & 3374 & 32.0 & 2107 & 20.0 & 10528 & 100.0
\end{tabular}

Age, years

\begin{tabular}{lcccccccccc}
\hline $50-59$ & 530 & 15.8 & 372 & 11.1 & 1770 & 52.7 & 687 & 20.5 & 3359 & 31.9 \\
\hline $60-69$ & 791 & 21.4 & 915 & 24.7 & 1179 & 31.8 & 817 & 22.1 & 3702 & 35.2 \\
\hline $70-79$ & 568 & 22.7 & 1081 & 43.3 & 377 & 15.1 & 471 & 18.9 & 2497 & 23.7 \\
\hline$\geq 80$ & 218 & 22.5 & 572 & 59.0 & 48 & 4.9 & 132 & 13.6 & 970 & 9.2 \\
\hline Sex & & & & & & & & & & \\
\hline Male & 1171 & 22.3 & 1464 & 27.8 & 1697 & 32.3 & 928 & 17.6 & 5260 & 50.0 \\
\hline Female & 936 & 17.8 & 1476 & 28.0 & 1677 & 31.8 & 1179 & 22.4 & 5268 & 50.0
\end{tabular}

IMD quintile

\begin{tabular}{lllllllllll}
1 (least deprived) & 728 & 20.0 & 871 & 24.0 & 1306 & 35.9 & 729 & 20.1 & 3634 & 34.5 \\
\hline 2 & 491 & 19.8 & 674 & 27.1 & 825 & 33.2 & 496 & 20.0 & 2586 & 24.6 \\
\hline 3 & 426 & 20.2 & 598 & 28.3 & 662 & 31.4 & 425 & 20.1 & 2111 & 20.1 \\
\hline 4 & 302 & 19.9 & 510 & 33.6 & 410 & 27.0 & 296 & 19.5 & 1518 & 14.4 \\
\hline 5 (most deprived) & 160 & 20.5 & 287 & 36.8 & 171 & 22.0 & 161 & 20.7 & 779 & 7.4 \\
\hline
\end{tabular}

\section{Carer code}

\begin{tabular}{lcccccccccc}
\hline Present & 48 & 12.4 & 197 & 52.7 & 48 & 12.4 & 81 & 21.7 & 374 & 3.6 \\
\hline Not present & 2059 & 20.3 & 2743 & 27.0 & 3326 & 32.8 & 2026 & 20.0 & 10154 & 96.4
\end{tabular}

$B \& D=$ Barking and Dagenham. CPRD = Clinical Practice Research Datalink. IMD = Index of Multiple Deprivation. MLTCs = multiple long-term conditions. 


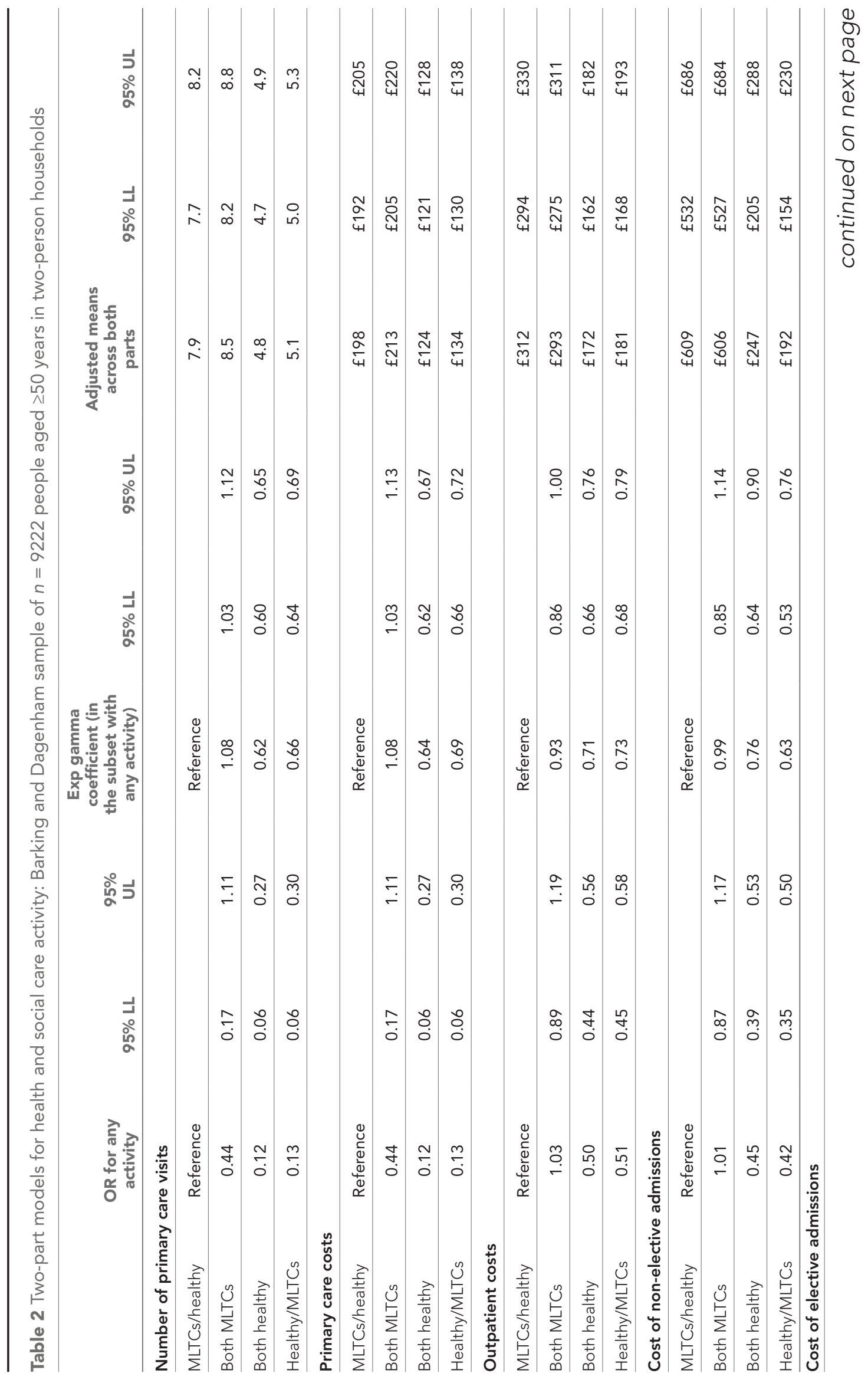




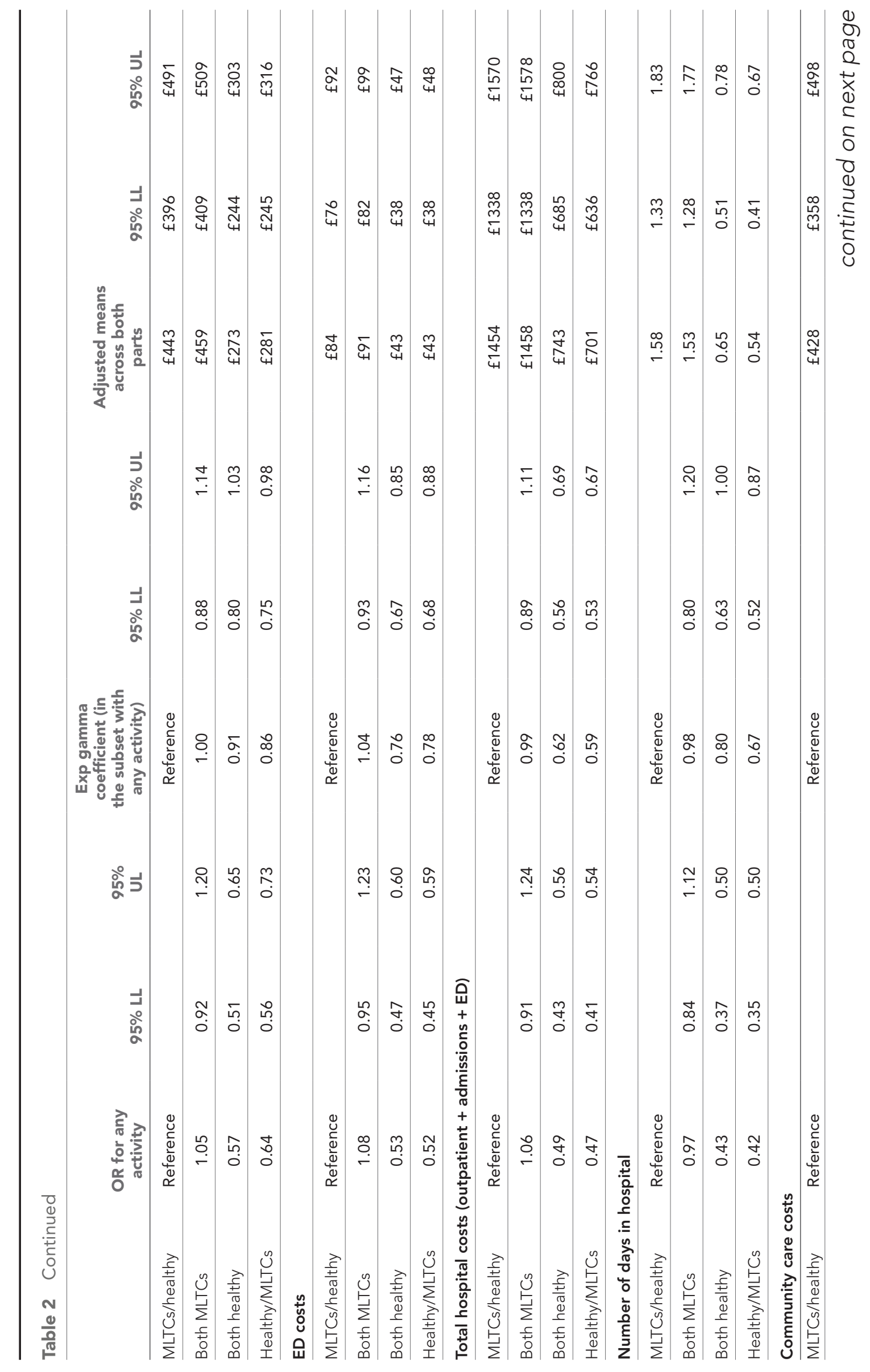




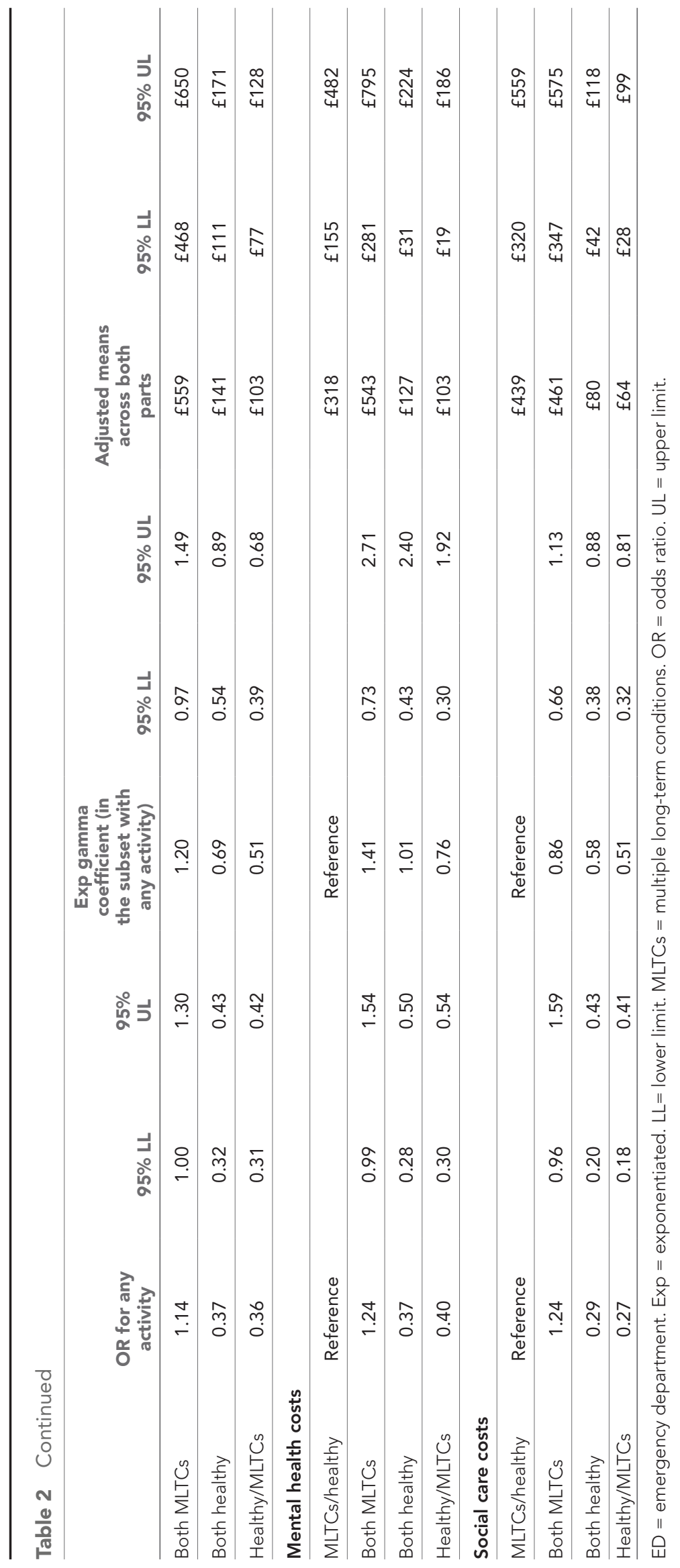




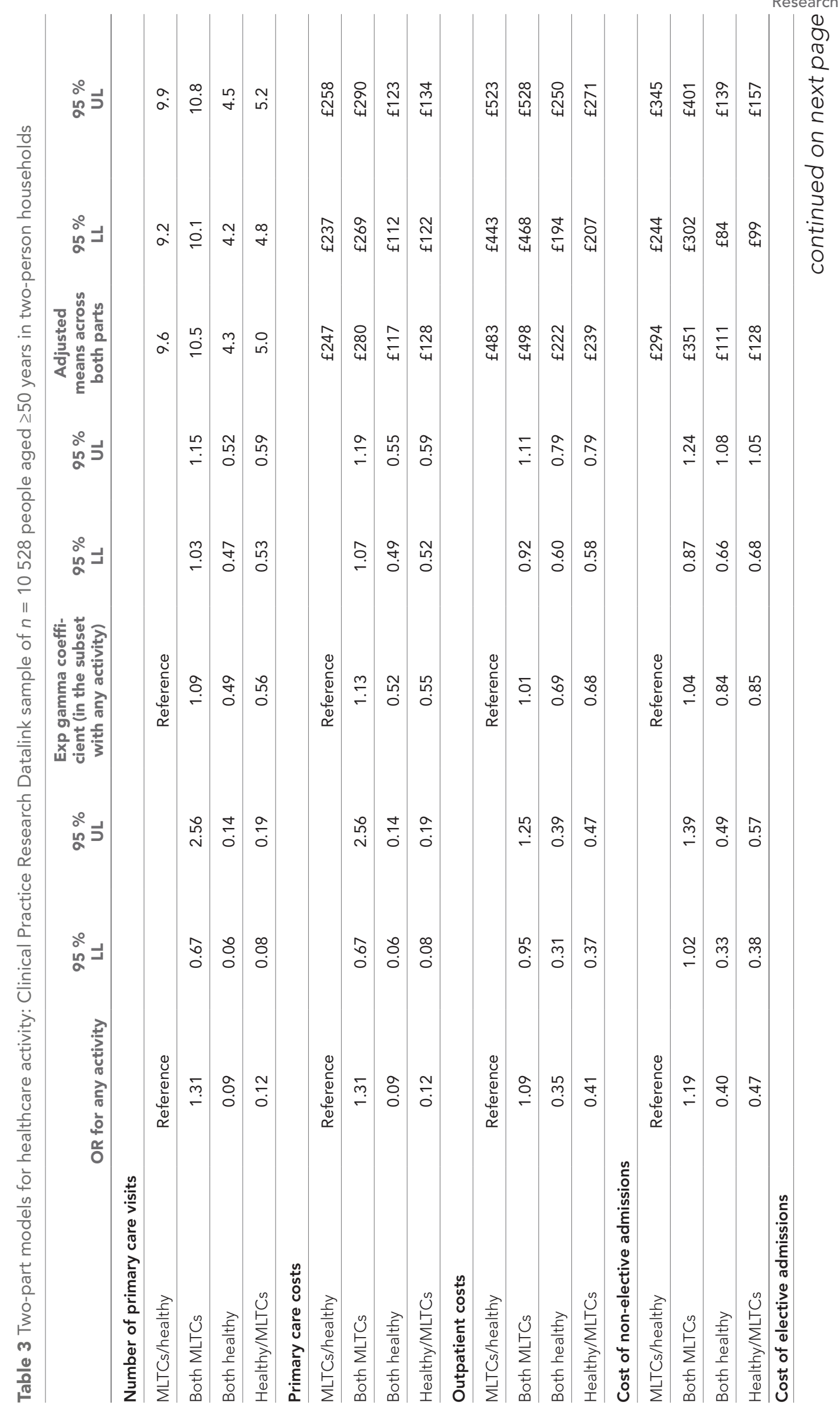




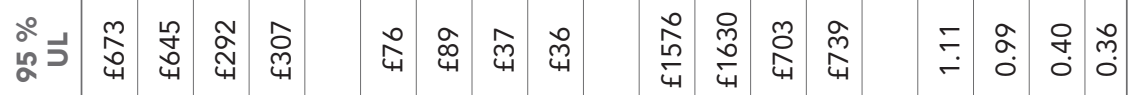

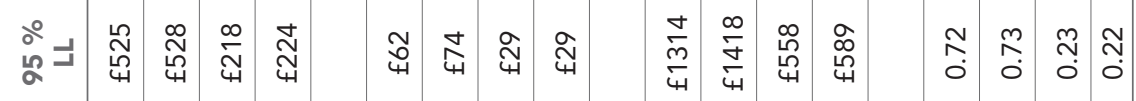

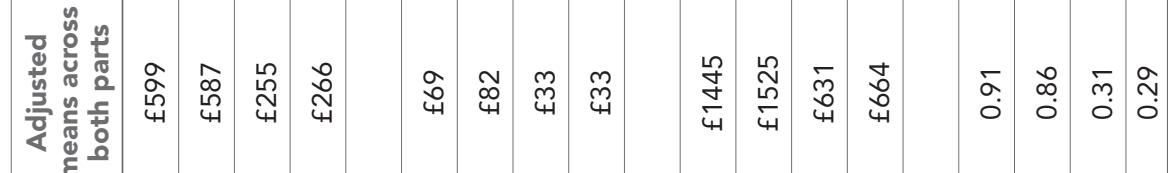

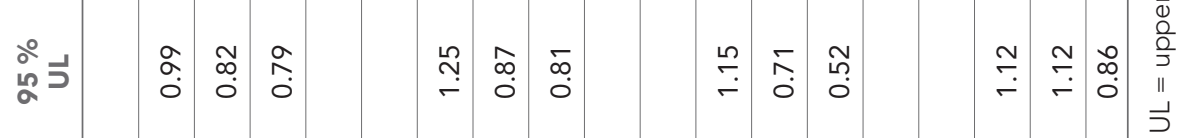

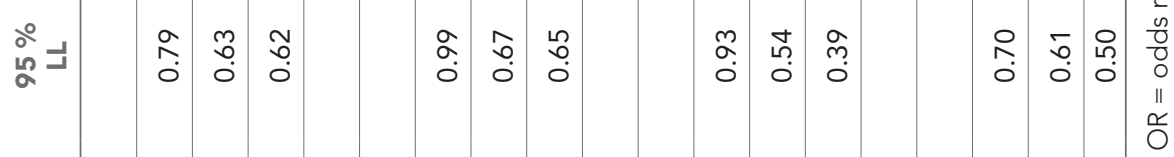

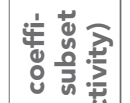

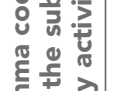

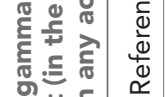

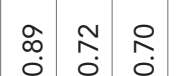

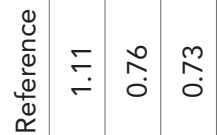

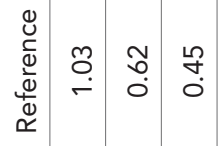

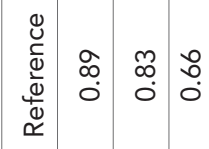

畜船考

(n)

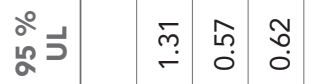

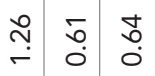

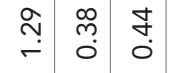

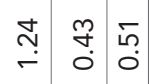

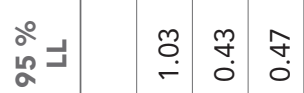

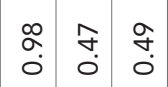

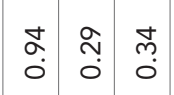

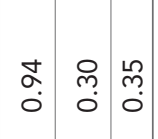

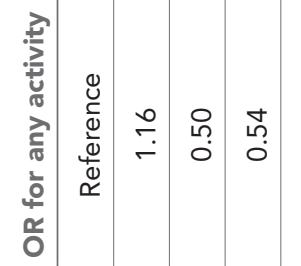

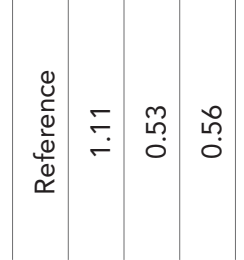

高

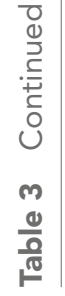

:

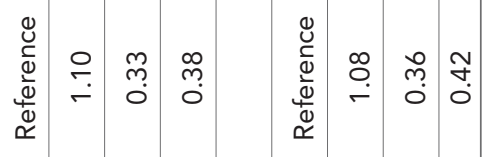

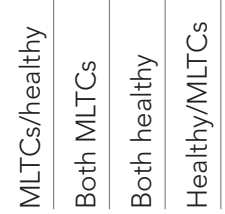

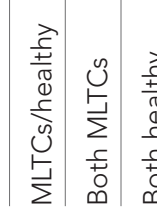

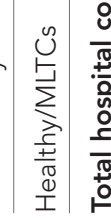

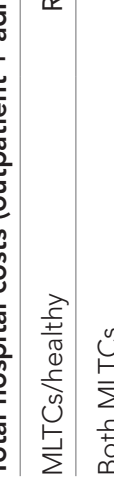

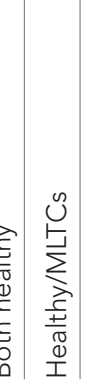

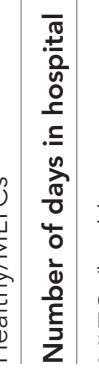

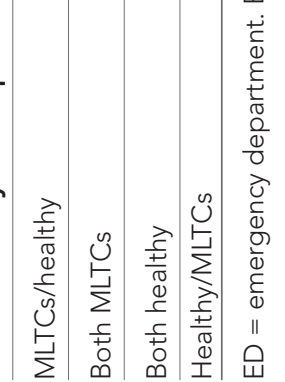




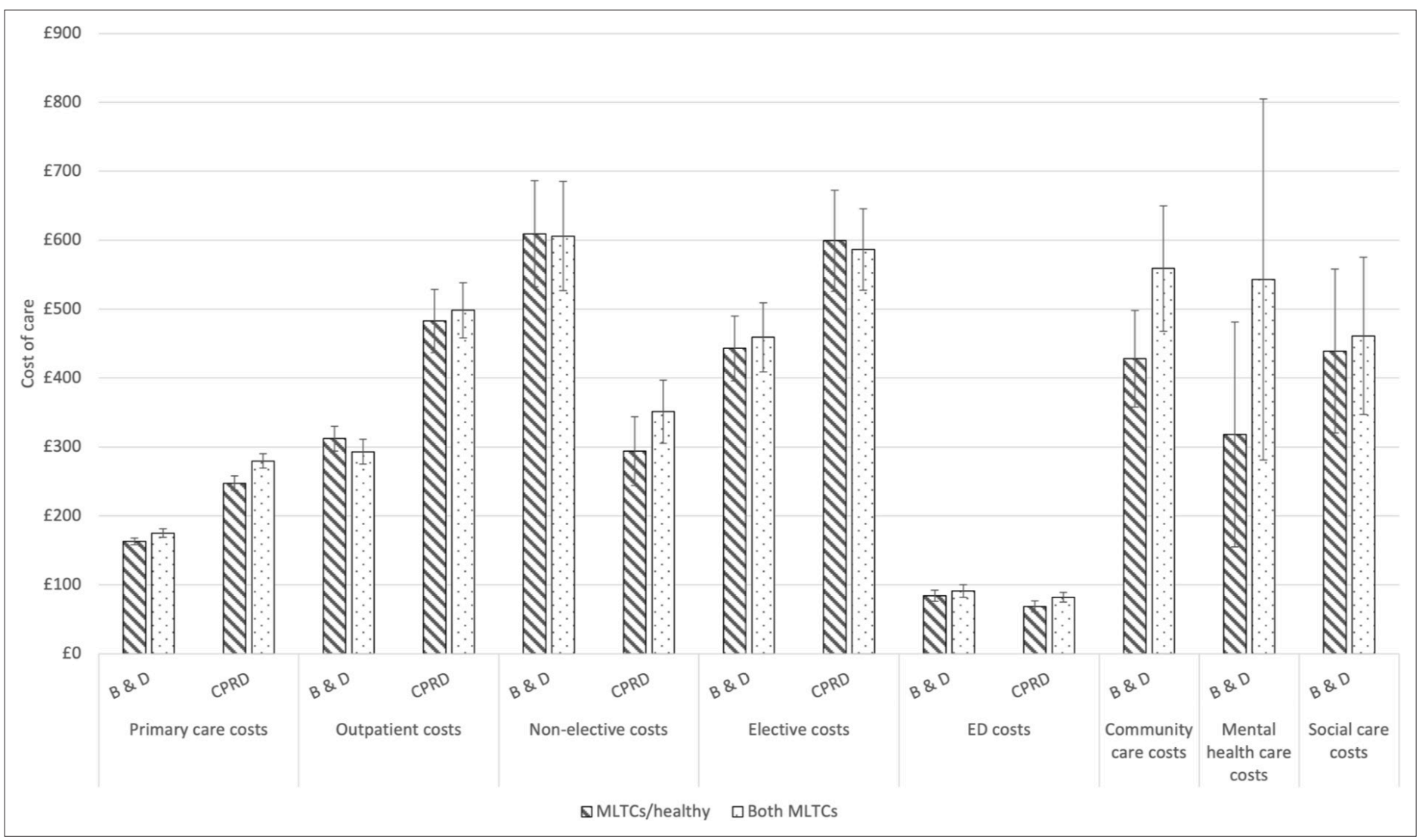

Figure 1 Cost of care by household multimorbidity status. B \& D = Barking and Dagenham. CPRD = Clinical Practice Research Datalink. ED = emergency department. MLTCs = multiple long-term conditions.

For those with any activity, exponentiated gamma coefficients show the association between household MLTC status and level of care activity or cost. The coefficient of $1.08(95 \% \mathrm{Cl}=1.03$ to 1.12) for primary care visits shows the number of visits for the Both MLTCs group was $8 \%(95 \% \mathrm{Cl}=3 \%$ to $12 \%)$ higher than the reference group. A similar difference in cost of primary care visits was seen. There was no evidence of difference in costs between these groups for other outcomes.

The adjusted means combine estimates from both parts of the model, including those with and without the relevant activity. Adjusted mean annual primary care costs and number of visits were higher for the Both MLTCs group than the reference. Community care costs for the Both MLTCs group were also higher ( $₫ 559$ versus $£ 428$ ), as were mental health care costs ( $₫ 543$ versus $£ 318$ ), although Cls overlapped (Figure 1).

Although not the focus of this study, those without MLTCs (in the Both healthy or the Healthy/ MLTCs group) were less likely to have any activity than the reference group and had lower adjusted mean costs for all types of care.

\section{Replication in the national sample}

The national sample was younger than the main sample ( $32 \%$ versus $25 \%$ aged $50-59$ years) and less socioeconomically deprived (Table 1). The prevalence of MLTCs was $48 \%$ in the national sample and $58 \%$ of people with MLTCs were co-resident with another person with MLTCs. The Both MLTCs group was more likely to have a non-elective hospital admission (odds ratio [OR] $=1.19[95 \% \mathrm{Cl}=1.02$ to 1.39]) or elective admission and somewhat more likely to have any ED visit $(\mathrm{OR}=1.11[95 \% \mathrm{Cl}=0.98$ to 1.26]) compared with the reference group (Table 3).

In the subset with non-zero cost or activity, primary care costs were $13 \%(95 \% \mathrm{Cl}=7 \%$ to $19 \%)$ higher in the Both MLTCs group compared with the reference, and the Both MLTCs group also had more primary care visits. There was a suggestion of higher ED costs (exponentiated gamma coefficient $1.11[95 \% \mathrm{Cl}=0.99$ to $1.25, P=0.06]$ ) with no evidence of difference in costs between these groups for other outcomes. 
As in the local sample, combined estimates across both parts of the model showed significantly higher adjusted primary care costs and number of visits for the Both MLTCs group (10.5 visits) than the reference ( 9.6 visits).

\section{Discussion}

\section{Summary}

This study shows that the household context matters for the care use of people with MLTCs, independently of age, sex, and area deprivation. Evidence from one local and one national sample showed higher primary care costs and visits where two people with MLTCs were co-resident. Where data were available (in the local sample only), these showed a greater likelihood of using community care activity and a trend towards greater likelihood of using mental health care where two people with MLTCs were co-resident. Differences in secondary care according to the co-resident's MLTC status were inconsistent in direction in the local and national datasets, although both showed a trend to slightly higher ED costs where two people with MLTCs were co-resident.

\section{Strengths and limitations}

Two-part models were used to model cost and utilisation outcomes. Outcomes were based on EHRs and not subject to recall or reporting bias. Two large samples were used to test the hypothesis, with similar prevalence of own and co-resident MLTCs. The findings were able to be replicated in a national sample for primary care. This provides reassurance that the pseudonymised variable based on the first line of the patient's last known address in combination with current registration date is a reasonable approach to identifying two-person households in primary care records.

While novel data linkage allowed the examination of mental health, community, and social care in Barking and Dagenham, these data are not available nationally. Replication in other local sites is needed to assess whether higher levels of community and mental health care use where both people in a two-person household have MLTCs are seen in other contexts.

Partners could not be distinguished from other types of co-resident as partnership status is infrequently recorded in EHRs. ${ }^{17}$ The influence of a partner may be different from that of a nonintimate co-resident, although short-term co-residents are probably rare among those aged $\geq 50$ years. Neither could the authors identify informal caregivers because this also is not well recorded in administrative records. In this study, $<5 \%$ had a Read code relating to caring whereas the 2011 census found over $17 \%$ of people aged $\geq 50$ years in England were providing informal care for someone with a long-term physical or mental health condition or disability. ${ }^{18}$

The number or severity of conditions or acquisition of new conditions through follow-up were not considered, although the adjustment for age and socioeconomic deprivation may partly capture this. Different lists of conditions were used in the two datasets, but there was considerable overlap and the main comparison of interest for this study was within-dataset differences between the Both MLTCs and reference groups. These findings should not be extrapolated to younger households, although household health context has previously been associated with children's healthcare use. ${ }^{19}$

\section{Comparison with existing literature}

Although unobserved confounding cannot be excluded, there are three substantive mechanisms that could underlie observed associations. These are tentative and were not directly tested in this study. First, a co-resident with MLTCs may have less capacity to provide informal support than a healthy coresident. Lack of informal support has sometimes been associated with greater healthcare utilisation. ${ }^{20}$ The substitution of informal and formal care may depend on the specific type of healthcare utilisation. A study based in the US found evidence of substitution for home health, nursing home care, and physician visits but not for secondary care. ${ }^{21}$ Community care investigated in the present study could be considered broadly equivalent to home health care in the US, in which case the finding that community care and primary care costs varied according to the co-resident's health status, but hospital costs did not, shows alignment with the US study if co-residents' health status is an indicator of informal support provision. Researchers have proposed that informal care and hospital care are different products so substitution of one for the other would not be expected. ${ }^{21}$ 
A second plausible explanation is that a co-resident with MLTCs has more information about available health services based on the management of their own long-term conditions than one who does not have MLTCs. There is evidence that caregivers can act as advocates in ways that increase some types of care use, by helping a patient overcome denial about their need for care or being more proactive in seeking help, ${ }^{21}$ although it is not known whether this advocacy role depends on the caregiver's health status.

A third possible explanation is that the person with MLTCs may be providing care for their coresident with MLTCs. Caregiving can be a stressful experience with negative health consequences, especially in the context of low levels of formal care, ${ }^{22}$ and this could contribute to increased use of health care, although carers have reported greater difficulty accessing primary care compared with non-carers, ${ }^{23}$ and may avoid treatment because of their caring responsibilities. ${ }^{24}$ This third explanation is supported by the data in the present study showing that a healthy person co-resident with a person with MLTCs also had higher primary care costs and more primary care visits than their counterparts co-resident with a healthy person.

\section{Implications for research and practice}

The largest cost differences between a person with MLTCs co-resident with a healthy person and one co-resident with another person with MLTCs were for community care and mental health care. However, most people did not have any activity for these services and consequently, confidence intervals were wide. It was not possible to replicate this in CPRD and this highlights the need for programmes to facilitate national linkage of primary, secondary, community, and social care. ${ }^{25}$

The findings raise questions about how to deliver health and social care that acknowledges the household context for people with MLTCs. This could include more systematic use of information about the health status of patients and their co-residents for efficient scheduling of community care for people with MLTCs, potentially reducing the total number of visits to a household that would be needed and enabling community care practitioners to increase the amount of time spent with patients in their home. It could also include developing healthcare initiatives to households based on the principles of the group care approach. ${ }^{26}$ In group consultations, multiple patients see $\geq 1$ clinicians together. This combines features of the clinician-patient consultation with features of patient support groups, ${ }^{27}$ and has the potential to increase available consultations and peer support. If this is to be achieved, then household context data will need to be made available to service providers within integrated care systems. This will require information governance standards to be upheld while at the same time ensuring household data can be shared for patient and public benefit.

The findings reaffirm the importance of identifying and supporting those who receive and/or provide informal care. Although carer status was not able to be examined, the high level of MLTCs within households (around 50\% of patients with MLTCs in these samples are living with another person with MLTCs) suggests that some carers may be managing complex care for themselves and their care recipients. The NHS Long Term Plan $^{28}$ and other government initiatives ${ }^{29}$ commit to better identifying and supporting carers, and the present study suggests this has the potential to benefit people living with MLTCs as both givers and recipients of informal care.

The number of people with MLTCs is rising and the study suggests that MLTCs may cluster in households. These trends potentially impact on care systems, notably primary care and community care, and treatment burden for patients. In addition to preventive measures to modify risk factors that are common within households, ${ }^{30}$ research is needed to test whether connecting service input across household members could lead to efficiency savings for health and care service providers, or reduce treatment burden for those living with MLTCs.

\section{Funding}

The authors received no financial support for the research, authorship, or publication of this article.

\section{Ethical approval}

This work uses data provided by patients and collected by the NHS as part of their care and support. Use of the national data was approved by the CPRD independent scientific advisory committee (ISAC protocol number 17_150RMn2).

\section{Provenance}


Freely submitted; externally peer reviewed.

\section{Acknowledgements}

The authors would like to thank Dr Manuel Gomes for his advice on the analysis and writing up of this work. They would also like to thank the Data Management Team at The Health Foundation for their work managing the data sharing process.

\section{References}

1. Cassell A, Edwards D, Harshfield A, et al. The epidemiology of multimorbidity in primary care: a retrospective cohort study. Br J Gen Pract 2018; 68(669): e245-e251. DOI: https://doi.org/10.3399/bjgp18X695465

2. Stafford $M$, Steventon A, Thorlby $R$, et al. Understanding the health care needs of people with multiple health conditions. 2018; https://www.health.org.uk/publications/understanding-the-health-care-needs-of-people-withmultiple-health-conditions (accessed 11 Feb 2021).

3. Kasteridis P, Street A, Dolman M, et al. The importance of multimorbidity in explaining utilisation and costs across health and social care settings: evidence from South Somerset's Symphony Project. 2014; http://eprints.whiterose. ac.uk/136185/1/CHERP96_multimorbidity_utilisation_costs_health_social_care.pdf (accessed 11 Feb 2021).

4. Lloyd T, Brine R, Pearson R, et al. The impact of integrated care teams on hospital use in North East Hampshire and Farnham. Consideration of findings from the Improvement Analytics Unit. 2018; https://www.health.org.uk/ publications/impact-integrated-care-teams-hospital-use-north-east-hampshire-and-farnham (accessed 11 Feb 2021).

5. Sherlaw-Johnson C, Crump H, Arora S, et al. Patient-centred care for older people with complex needs: evaluation of a new care model in outer east London. 2018; https://www.nuffieldtrust.org.uk/research/patient-centred-carefor-older-people-with-complex-needs (accessed 11 Feb 2021).

6. Salisbury C, Man M-S, Bower P, et al. Management of multimorbidity using a patient-centred care model: a pragmatic cluster-randomised trial of the 3D approach. Lancet 2018; 392(10141): 41-50. DOI: https://doi.org/10. 1016/S0140-6736(18)31308-4

7. Health and Social Care Information Centre. Survey of carers in households 2009/10. 2010; https://files.digital.nhs. uk/publicationimport/pub02xxx/pub02200/surv-care-hous-eng-2009-2010-rep1.pdf (accessed 11 Feb 2021).

8. Hopman P, Heins MJ, Korevaar JC, et al. Health care utilization of patients with multiple chronic diseases in the Netherlands: differences and underlying factors. Eur J Intern Med 2016; 35: 44-50. DOI: https://doi.org/10.1016/j. ejim.2016.08.025

9. Meyler D, Stimpson JP, Peek MK. Health concordance within couples: a systematic review. Soc Sci Med 2007; 64(11): 2297-2310. DOI: https://doi.org/10.1016/j.socscimed.2007.02.007

10. Patel SA, Dhillon PK, Kondal D, et al. Chronic disease concordance within Indian households: a cross-sectional study. PLoS Med 2017; 14(9): e1002395. DOI: https://doi.org/10.1371/journal.pmed.1002395

11. Campbell P, Shraim M, Jordan KP, Dunn KM. In sickness and in health: a cross-sectional analysis of concordance for musculoskeletal pain in 13,507 couples. Eur J Pain 2016; 20(3): 438-446. DOI: https://doi.org/10.1002/ejp.744

12. Payne G, Laporte A, Deber R, Coyte PC. Counting backward to health care's future: using time-to-death modeling to identify changes in end-of-life morbidity and the impact of aging on health care expenditures. Milbank Q 2007; 85(2): 213-257. DOI: https://doi.org/10.1111/j.1468-0009.2007.00485.x

13. Barnett K, Mercer SW, Norbury M, et al. Epidemiology of multimorbidity and implications for health care, research, and medical education: a cross-sectional study. Lancet 2012; 380(9836): 37-43. DOI: https://doi.org/10.1016/ S0140-6736(12)60240-2

14. Payne RA, Mendonca SC, Elliott MN, et al. Development and validation of the Cambridge multimorbidity score. CMAJ 2020; 192(5): E107-E114. DOI: https://doi.org/10.1503/cmaj.190757

15. Herrett E, Gallagher AM, Bhaskaran K, et al. Data resource profile: Clinical Practice Research Datalink (CPRD). Int J Epidemiol 2015; 44(3): 827-836. DOI: https://doi.org/10.1093/ije/dyv098

16. University of Cambridge, Department of Public Health and Primary Care. CPRD at Cambridge - code lists; http:// www.phpc.cam.ac.uk/pcu/cprd_cam/codelists (accessed 11 Feb 2021).

17. Jain $A$, van Hoek AJ, Walker JL, et al. Identifying social factors amongst older individuals in linked electronic health records: an assessment in a population based study. PLoS One 2017; 12(11): e0189038. DOI: https://doi.org/10. 1371/journal.pone.0189038

18. nomis. LC3301EW Provision of unpaid care by general health by sex by age; https://www.nomisweb.co.uk/census/ 2011/lc3301ew (accessed 11 Feb 2021).

19. Dreyer K, Williamson RAP, Hargreaves DS, et al. Associations between parental mental health and other family factors and healthcare utilisation among children and young people: a retrospective, cross-sectional study of linked healthcare data. BMJ Paediatr Open 2018; 2(1): e000266. DOI: https://doi.org/10.1136/bmjpo-2018-000266

20. Babitsch B, Gohl D, von Lengerke T. Re-revisiting Andersen's behavioral model of health services use: a systematic review of studies from 1998-2011. Psychosoc Med 2012; 9: Doc11. DOI: https://doi.org/10.3205/psm000089

21. Van Houtven $\mathrm{CH}$, Norton EC. Informal care and health care use of older adults. J Health Econ 2004; 23(6): 1159_ 1180. DOI: https://doi.org/10.1016/j.jhealeco.2004.04.008

22. Wagner $M$, Brandt $M$. Long-Term care provision and the well-being of spousal caregivers: an analysis of 138 European regions. J Gerontol B Psychol Sci Soc Sci 2018; 73(4): e24-e34. DOI: https://doi.org/10.1093/geronb/ gbx 133 
23. Thomas GPA, Saunders CL, Roland MO, Paddison CAM. Informal carers' health-related quality of life and patient experience in primary care: evidence from 195,364 carers in England responding to a national survey. BMC Fam Pract 2015; 16(1): 62. DOI: https://doi.org/10.1186/s12875-015-0277-y

24. Tommis $Y$, Robinson $C A$, Seddon $D$, et al. Carers with chronic conditions: changes over time in their physical health. Chronic Illn 2009; 5(3): 155-164. DOI: https://doi.org/10.1177/1742395309339251

25. NHS England, Local Government Association. Local health and care record exemplars: a summary; https://www. england.nhs.uk/wp-content/uploads/2018/05/local-health-and-care-record-exemplars-summary.pdf (accessed 11 Feb 2021).

26. Edelman D, McDuffie JR, Oddone E, et al. Shared medical appointments for chronic medical conditions: a systematic review. 2012; https://www.hsrd.research.va.gov/publications/esp/shared-med-appt.pdf (accessed 11 Feb 2021).

27. Jones T, Darzi A, Egger G, et al. Process and systems: a systems approach to embedding group consultations in the NHS. Future Healthc J 2019; 6(1): 8-16. DOI: https://doi.org/10.7861/futurehosp.6-1-8

28. NHS England. The NHS Long Term Plan. 2019; www.longtermplan.nhs.uk (accessed 11 Feb 2021).

29. Department of Health and Social Care. Carers action plan 2018 to 2020: supporting carers today. 2018; https:// www.gov.uk/government/publications/carers-action-plan-2018-to-2020 (accessed 11 Feb 2021).

30. The Academy of Medical Sciences. Multiple morbidities as a global health challenge. 2015; https://acmedsci.ac.uk/ file-download/38330-567965102e84a.pdf (accessed 11 Feb 2021). 